Issued by Sandia National Laboratories, operated for the United States Department of Energy by Sandia Corporation.

NOTICE: This report was prepared as an account of work sponsored by an agency of the United States Government. Neither the United States Government, nor any agency thereof, nor any of their employees, nor any of their contractors, subcontractors, or their employees, make any warranty, express or implied, or assume any legal liability or responsibility for the accuracy, completeness, or usefulness of any information, apparatus, product, or process disclosed, or represent that its use would not infringe privately owned rights. Reference herein to any specific commercial product, process, or service by trade name, trademark, manufacturer, or otherwise, does not necessarily constitute or imply its endorsement, recommendation, or favoring by the United States Government, any agency thereof, or any of their contractors or subcontractors. The views and opinions expressed herein do not necessarily state or reflect those of the United States Government, any agency thereof, or any of their contractors.

Printed in the United States of America. This report has been reproduced directly from the best available copy.

Available to DOE and DOE contractors from

Office of Scientific and Technical Information

P.O. Box 62

Oak Ridge, TN 37831

Prices available from (703) 605-6000

Web site: http://www.ntis.gov/ordering.htm

Available to the public from

National Technical Information Service

U.S. Department of Commerce

5285 Port Royal Rd

Springfield, VA 22161

NTIS price codes

Printed copy: A03

Microfiche copy: A01

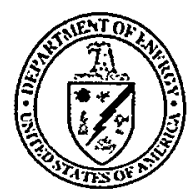




\section{DISCLAIMER}

Portions of this document may be illegible in electronic image products. Images are produced from the best available original document. 
SAND99-1648

Unlimited Release

Printed July 1999

\title{
A Glove Box Enclosed Gas-Tungsten Arc Welding System
}

\author{
M. Reece and C. V. Robino \\ Materials Joining Department \\ Sandia National Laboratories \\ P.O. Box 5800 \\ Albuquerque, NM 87185-0367
}

\begin{abstract}
This report describes an inert atmosphere enclosed gas-tungsten arc welding system which has been assembled in support of the MC2730, MC2730A and MC 3500 Radioisotope Thermoelectric Generator (RTG) Enhanced Surveillance Program. One goal of this program is to fabricate welds with microstructures and impurity levels which are similar to production heat source welds previously produced at Los Alamos National Laboratory and the Mound Facility. These welds will subsequently be used for high temperature creep testing as part of the overall component lifetime assessment. In order to maximize the utility of the welding system, means for local control of the arc atmosphere have been incorporated and a wide range of welding environments can easily be evaluated. The gas-tungsten arc welding system used in the assembly is computer controlled, includes two-axis and rotary motion, and can be operated in either continuous or pulsed modes. The system can therefore be used for detailed research studies of welding impurity effects, development of prototype weld schedules, or to mimic a significant range of production-like welding conditions. Fixturing for fabrication of high temperature creep test samples have been designed and constructed, and weld schedules for griptab and test welds have been developed. The microstructures of these welds have been evaluated and are consistent with those used during RTG production.
\end{abstract}




\section{Introduction}

Radioisotope thermoelectric generators (RTGs) such as the MC2730 and MC3500 are electrical power sources which essentially consist of a radioisotope heat source in contact with a thermocouple pile. The heat sources used in these in RTGs, such as the MC 2893, MC2893A, and MC3599, are plutonium oxide fuel encased within a welded tantalum alloy (T-111) capsule. During stockpile life, decay products from the plutonium oxide result in an increasing pressure within the capsule which must be contained during both normal operation and accidental fire exposure. Of these, the most important is the fire exposure since high temperatures can result in creep of the T-111 alloy, generally within the welds, and potential leakage from the capsule. Welding changes the properties of the alloy, and can result in an unexpected failure location during simulated fire testing.

Current surveillance activities include periodic pressure burst testing of inert capsules pressurized to the expected end-of-life pressure. However, there is significant variability in the qualification and pressure burst data, it is not fully predictive, and it does not explicitly incorporate materials aging. To overcome these difficulties, an enhanced surveillance program has been initiated to improve understanding of creep and aging of T-111 welds. The program consists of several major parts, including: characterization of creep deformation and failure modes and development of weldment creep data for T-111 welds; evaluation of potential weld aging mechanisms; development of improved thermal and mechanical response models; and correlation with qualification and conventional surveillance tests. In order to accomplish these tasks, welds must be produced which have microstructures and characteristics which are similar to those in the production heat sources. Since the conditions under which the heat sources are not known in complete detail, it is desirable to have a welding system capable of beingrapidly reconfigured to mimic the various possible production environments. Further, as discussed below, T-111 alloy welds are very sensitive to oxygen and nitrogen content. Thus, it is also desirable to provide a means in the welding chamber for precise control of the local composition of the welding atmosphere.

The tantalum alloy designated T-111 (Ta-8W-2Hf) was developed by Westinghouse Astronuclear Laboratory in support of the Space Nuclear Power Conversion System program in the early 1960 's. ${ }^{(1,2)}$ Tantalum and its alloys are useful in such applications, despite their high density $\left(0.604 \mathrm{lbs} . / \mathrm{in}^{3}\right.$. almost twice that of molybdenum or columbium alloys), because of their 
weldability and low temperature ductility combined with strength retention to $1370^{\circ} \mathrm{C}$. These same qualities led to the choice of T-111 for the strength member in RTG heat sources. Research by General Electric on weldability of T-111 point to the need for close control of impurities in the weld atmosphere. ${ }^{(3)}$ Because of the hafnium content in T-111, their recommendation is for oxygen and atmospheric moisture to be maintained at less than $5 \mathrm{ppm}$ and nitrogen must also be kept at a very low level. Stoner and Lessmann ${ }^{(4)}$ and Stoner and Lessmann ${ }^{(5)}$ indicate that a total impurity level $\left(\mathrm{O}_{2}+\mathrm{H}_{2} \mathrm{O}\right)$ of $5 \mathrm{ppm}$ maximum should be maintained, and recommend a level of less that $1 \mathrm{ppm}$ where possible.

The Los Alamos National Laboratory weld schedule ${ }^{(6)}$ used for heat source production specified that oxygen, moisture, and nitrogen levels in the welding atmosphere be recorded for each weld, although records containing this information have not been located at the time of this writing. However, the progress report by Latimer and Reinhart ${ }^{(7)}$ and fabrication travelers indicate that typical impurity contents for the welding atmosphere used at Los Alamos were 2-5, 20-25, and 55-78 ppm for oxygen, water, and nitrogen respectively. The weld current levels, pulse rate, and rotational speed of the part were documented in the weld schedule, ${ }^{(6)}$ and these provided the baseline requirements for the current system.

\section{Glove Box Construction and Capabilities}

The Vacuum/Atmospheres HE-43-2 glove box was retrieved from storage and thoroughly cleaned. The He-43-2 is a single working-side box constructed from 3/16" 6061 aluminum. Its interior working space is 45 inches wide, 30 inches deep, and 33 inches high. Access to the interior is accomplished through a vacuum pump evacuated antechamber, 15 inches in diameter and 24 inches long. This box had previously seen service in the SNL welding shops, where it had been modified to accept a gas-tungsten arc (GTA) welding system by adding ports for power and cooling water. It proved necessary to replace the rubber gaskets around the windows and doors, and replace the gloves in order to seal the box. The extra ports were sealed with plugs and silicon caulk. The basic glove box and antechamber are shown in Figure 1. The purity of the inert atmosphere (argon) in the chamber is maintained by a Vacuum/Atmospheres Mo-40-2V Dri-Train. This is a high flow rate ( $40 \mathrm{cfm}$ argon) gas re-circulating system, which uses pure copper plated on alumina beads and micro-sieve beads to remove oxygen and moisture, 
respectively, to levels below $1 \mathrm{ppm}$. The Dri-Train system does not currently contain a nitrogen gettering system. The Dri-Train is rated to remove 32.5 liters of $\mathrm{O}_{2}$ and 364 liters of atmospheric moisture before it is necessary to regenerate the beads. The ball valves and pneumatic actuator valves were disassembled and cleaned, or replaced. The initial charge of beads proved impossible to regenerate, so it was replaced. Ultra-high purity argon and argon/3\% hydrogen regeneration gases for the system are supplied using commercial gas cylinders. As the system is currently configured, the nitrogen content of the box can be controlled only by repeated purging. Gas samples drawn before and after cycling 25 cubic feet ( volume of glove box) of gas through the interior, by evacuating the antechamber and allowing the pure refill gas from the cylinder to supply make-up gas, show that the $\mathrm{N}_{2}$ can be reduced to less than 5000 ppm by this method.

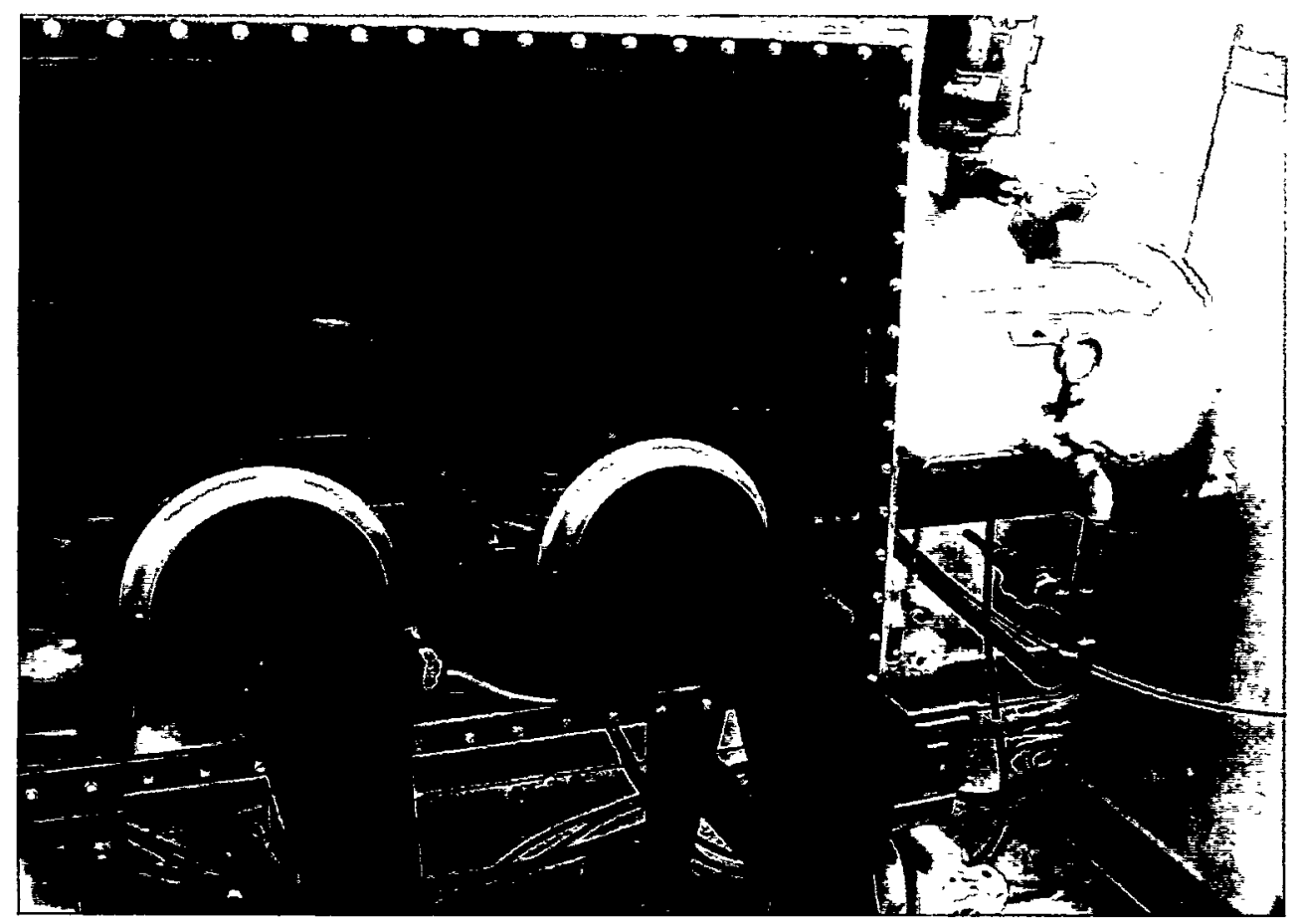

Figure 1. Glove box and antechamber.

Continuous sampling of the glove-box atmosphere by a Vacuum/ Atmospheres AO-316C Oxygen Analyzer offers real-time information on changes in the oxygen content. This analyzer is shown in Figure 2, and has four ranges: 0-10 ppm O, $0-100$ ppm O, $0-1000 \mathrm{ppm} \mathrm{O}_{2}$, 


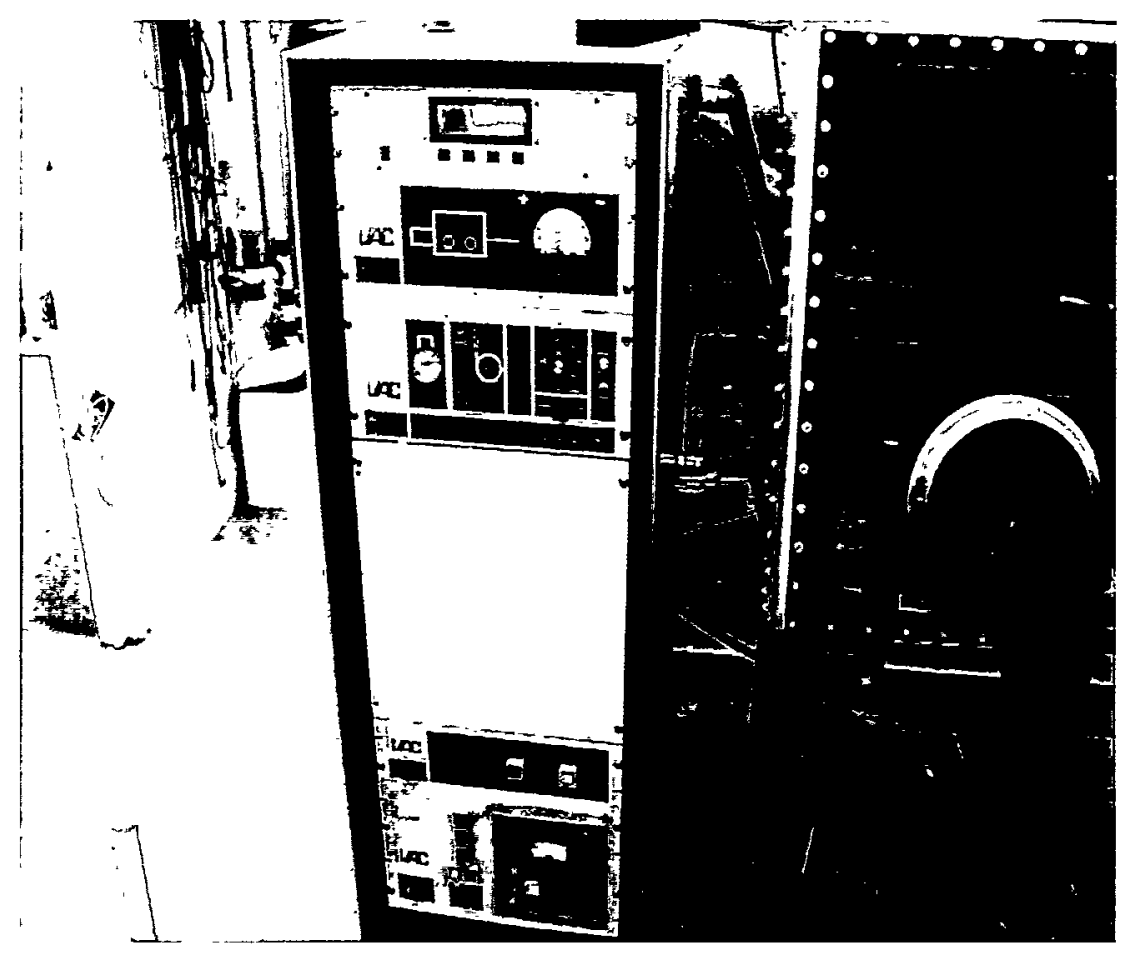

Figure 2. Dri-Train control unit.

and $0-10,000 \mathrm{ppm} \mathrm{O}_{2}$, and uses the Dri-Train regeneration gas for its zero reference. The higher ranges are very useful during the initial purge and fill of the box to monitor the effectiveness of the Dri-Train. Moisture levels are monitored with a Vacuum/Atmospheres Moisture 2000 which uses a NIST traceable thin-film on alumina oxide probe mounted in the back wall of the box. The Moisture 2000 has an effective range to less than $1 \mathrm{ppm}$, which is also displayed as a dew point reading from $-80^{\circ} \mathrm{C}$ to $20^{\circ} \mathrm{C}$. Typical operational oxygen and moisture levels for the system are 0.5 and $0.6 \mathrm{ppm}$, respectively.

A provision has been incorporated to allow separate shielding gas to be supplied directly from an external source to the torch head during welding. This approach, though somewhat less efficient than incorporation of a dedicated nitrogen gettering train into the glove box, has several advantages. First, the local atmosphere surrounding the welding arc can be extremely well controlled. Since the shielding gas is surrounded by the relatively high purity (and similar density) glove box gas, the entrainment of impurities into the arc is extremely small. Thus, impurities which are not scavenged by the Dri-Train system (such as nitrogen and hydrocarbons) are also effectively minimized in the weld atmosphere. Secondly, the ability to locally adjust the 
gas composition allows for detailed studies of the effects of shielding gas composition on weld properties. For example, the oxygen content in the atmosphere can be varied quickly and simply by adjusting the composition of the supply cylinder, rather than by adjusting the composition of the entire glove box atmosphere. Similarly, alternative shielding gases and gas mixtures, such as helium or argon/helium, can be readily used.

\section{Welding System}

The glove box was interfaced with a Weldlogic AWS-2000 automated GTA welding system, Figure 3. The AWS-2000 is a microcomputer based system, which allows the operator to control the arc gap, voltage, current configuration, shield gas delivery, wire feed, and X-Y travel. The unit is configured for a maximum operating current of $300 \mathrm{amps}$, which can be delivered in either a continuous or pulsed mode. The torch head is a Weldcraft WP-27ACC-12 air cooled machine GTA torch assembly rated for 500 -amp operation.

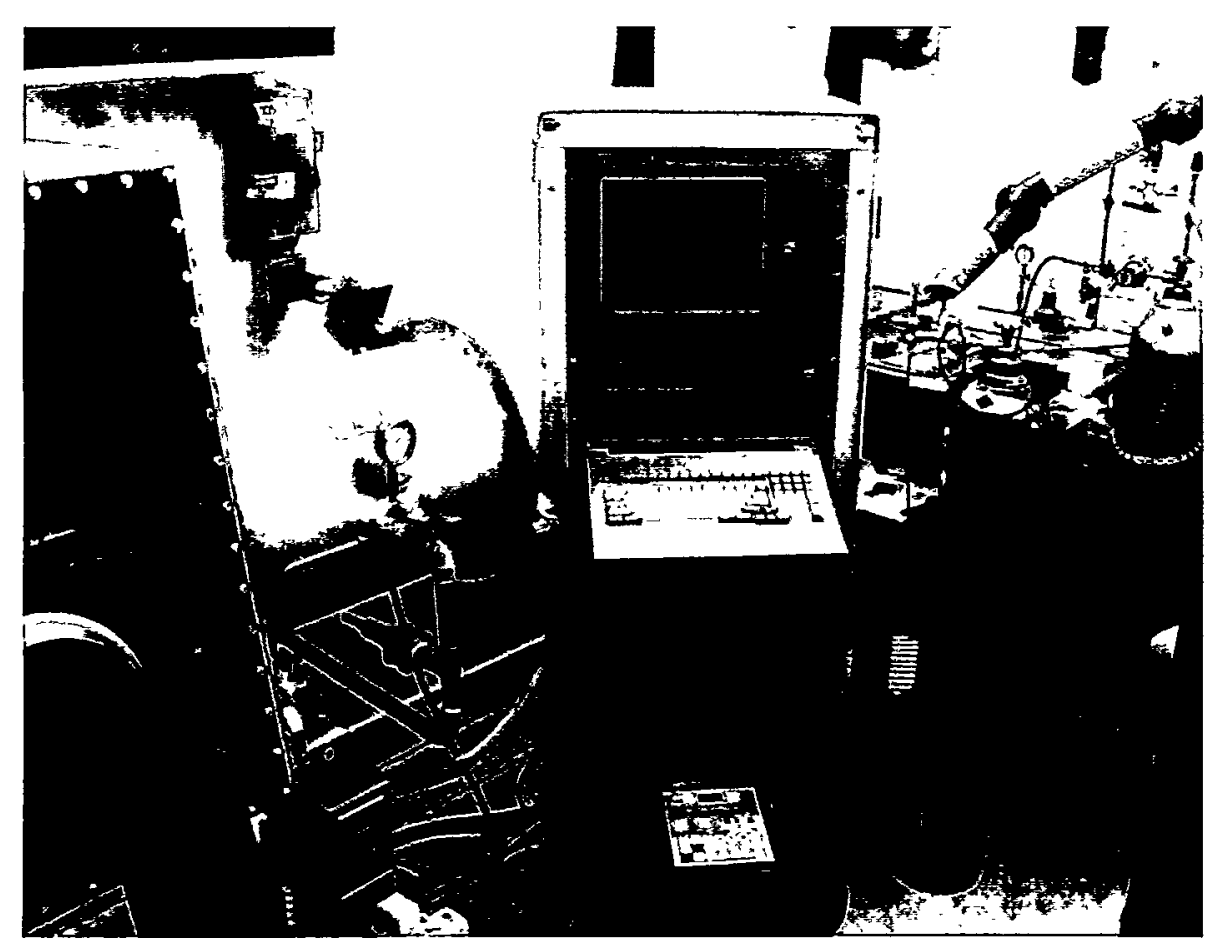

Figure 3. WeldLogic control panel. The external welding station is in the background. 
This unit is mated to a Compumotor driven $\mathrm{X}-\mathrm{Y}$ table, Figure 4, inside of the glove box which has an effective working area of 6"x 6". The X-Y table is isolated from the arc current by a 1" thick sheet of linen-based phenolic. A half inch thick 304 stainless steel breadboard with a side to side ground yoke to homogenize current flow provides both mounting locations for the work jigs, and a heat-sink. The fixtures used to hold the T-111 creep samples were also fabricated from 304 stainless steel. The $\mathrm{Z}$ axis control unit is mounted on a rigid arm extending from the back wall of the glove box. The torch can be rotated to a set angle relative to the work piece in the Z-X plane. The system can also be configured to control a rotary head.

The glove box is constructed as a separate welding station, and was interfaced with the welding system without alteration of the original external welding station. This included matching existing control cable and power connectors, so that either station can be quickly brought on line.

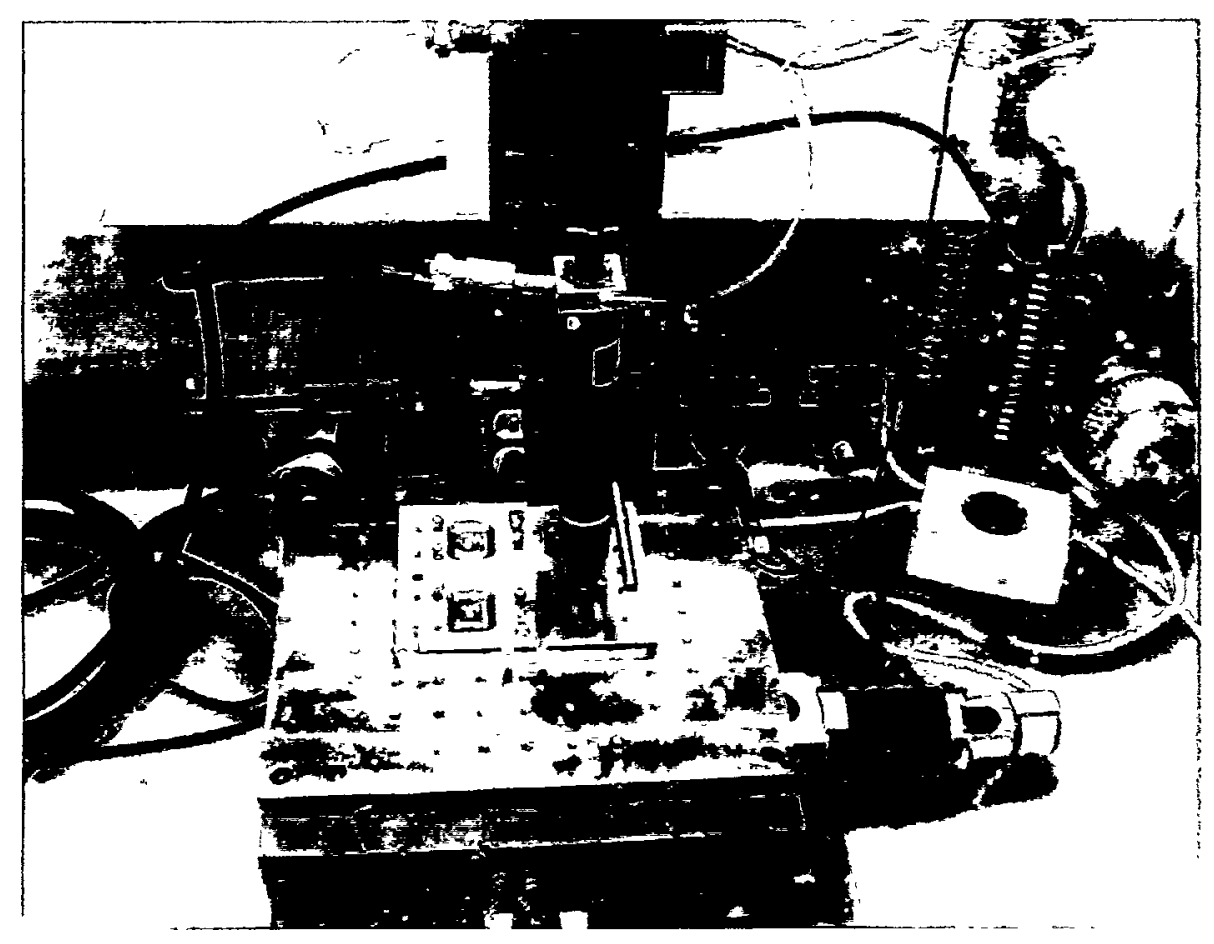

Figure 4. Torch head and X-Y table. 


\section{Operation and Weld Schedule Development}

In order to evaluate the basic system, trials were made at low amperage, using stainless steel and titanium test samples. It proved necessary to provide greater separation between the power cables and the control cables to prevent feedback to the computer control system. The Moisture 2000 is also sensitive to induced currents from the operation of the welding arc, so it is disabled prior to producing welds. These trials indicted that the welding atmosphere is sufficiently clean to produce bright and oxidation-free welds in reactive materials.

To conserve T-111 material, weld parameters were developed initially for Ta-10W alloy. This alloy has welding characteristics which are very similar to the T-111 alloy, and is more readily available. For the T-111 weld properties study, it was also decided to use a sample configuration in which the grip-tabs are constructed of Ta-10W alloy. The sample configuration is shown in Figure 5, and because the T-111 portion of the sample is rectangular in shape, there is nearly $100 \%$ utilization of T-111 material using this approach. Note also that Figure 5 shows the location of the transverse test weld bead at the center portion of the sample gage section (uppermost part). The sample piece part machining, cleaning, and final finishing procedures for fabrication of these samples are given in Appendix A. Figure 6 shows the weld layout at the grip-tab attachments, and illustrates that the welds are free from discoloration. In an effort to minimize heating of the gage section of the test samples and overall distortion, the grip-tab welds

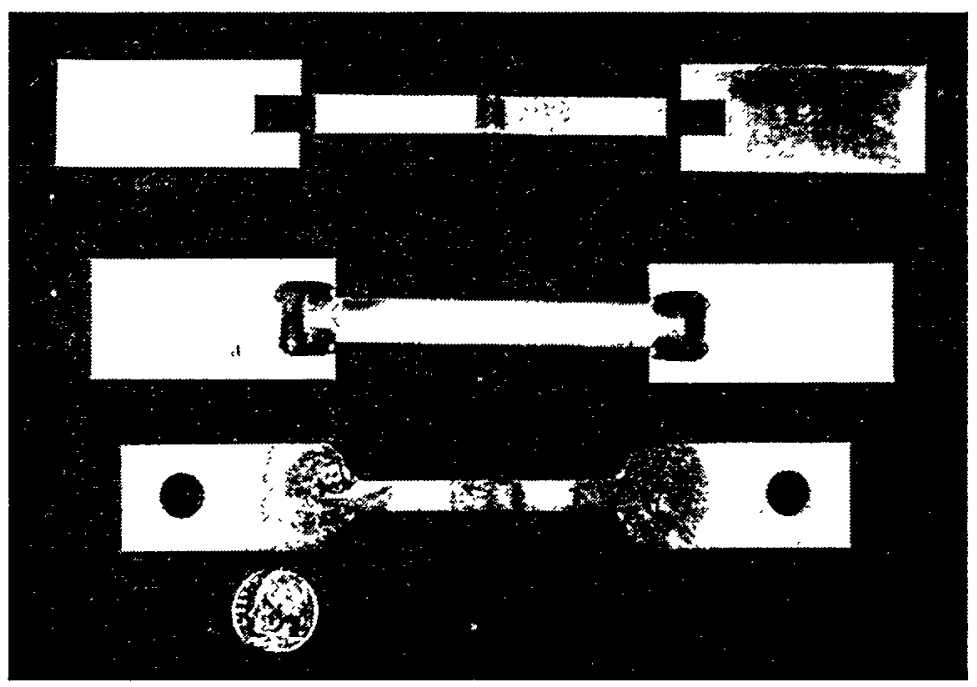

Figure 5. T-111 Creep test sample configuration. Note the transverse weld at the center of the gage section of the uppermost part. The part at the bottom of the figure has been chemically etched for testing. 


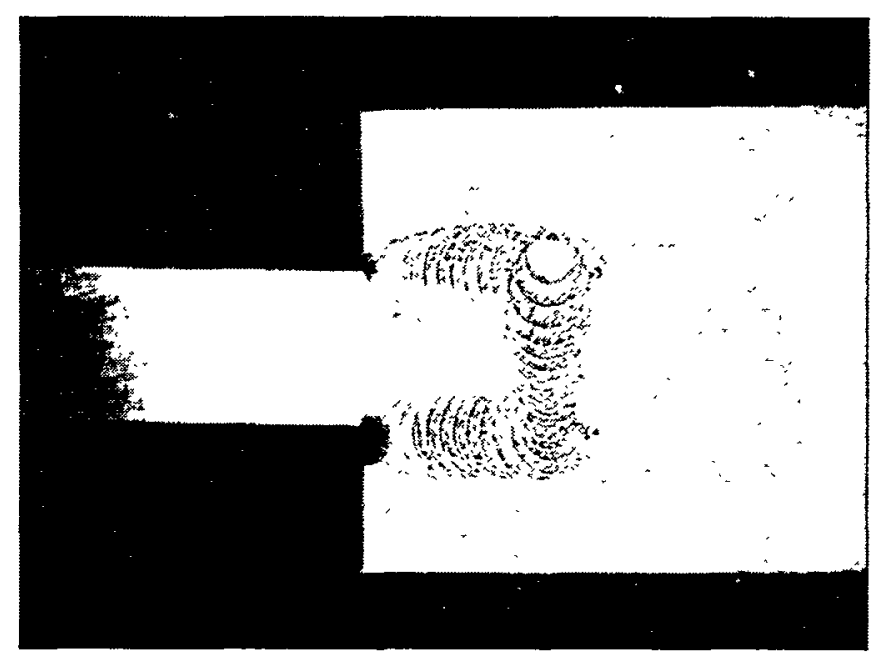

Figure 6 Detail of grip-tab segment welds.

are accomplished in short segments using pulsed current procedures, and the sample is allowed to cool between segments. The welding procedures are detailed in Appendix B. The weld penetration for each segment is approximately $60-80 \%$ of the thickness, and welds are made on both sides of the samples. Thus, six segment welds are required to complete each tab attachment. Preliminary creep testing of samples produced by this method indicate that the griptab attachment is of sufficient strength to accomplish the creep tests.

Figure 7 shows metallographic cross-sections of welds in Ta-10W. These welds were produced using the procedures given in Appendix B, and are very similar in structure to those used to produce the Milliwatt Heat Source strength member welds. The inter-pulse boundary spacing, grain size, and solidification cell spacing for these welds are all similar to that observed in sections of heat source surveillance samples ${ }^{(8)}$, and indicates that the current procedures are capable of reproducing the original production welds in terms of microstructure. Scanning electron microscope examinations of the test welds indicated that the solidification grain boundaries are essentially free of secondary constituents, indicating that the cleanliness of the welding atmosphere is acceptable for the heat source evaluations. Work is currently underway to validate these observations in the T-111 alloy, and to define procedures which are capable of mimicking the variability observed in typical production welds. 


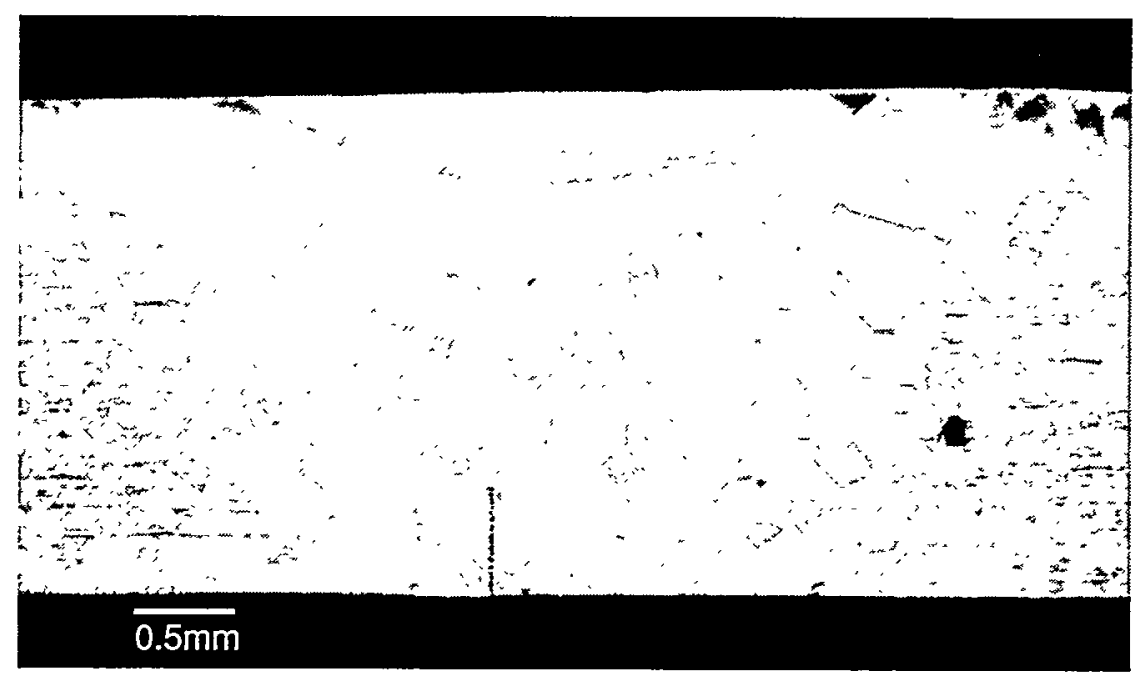

(a)

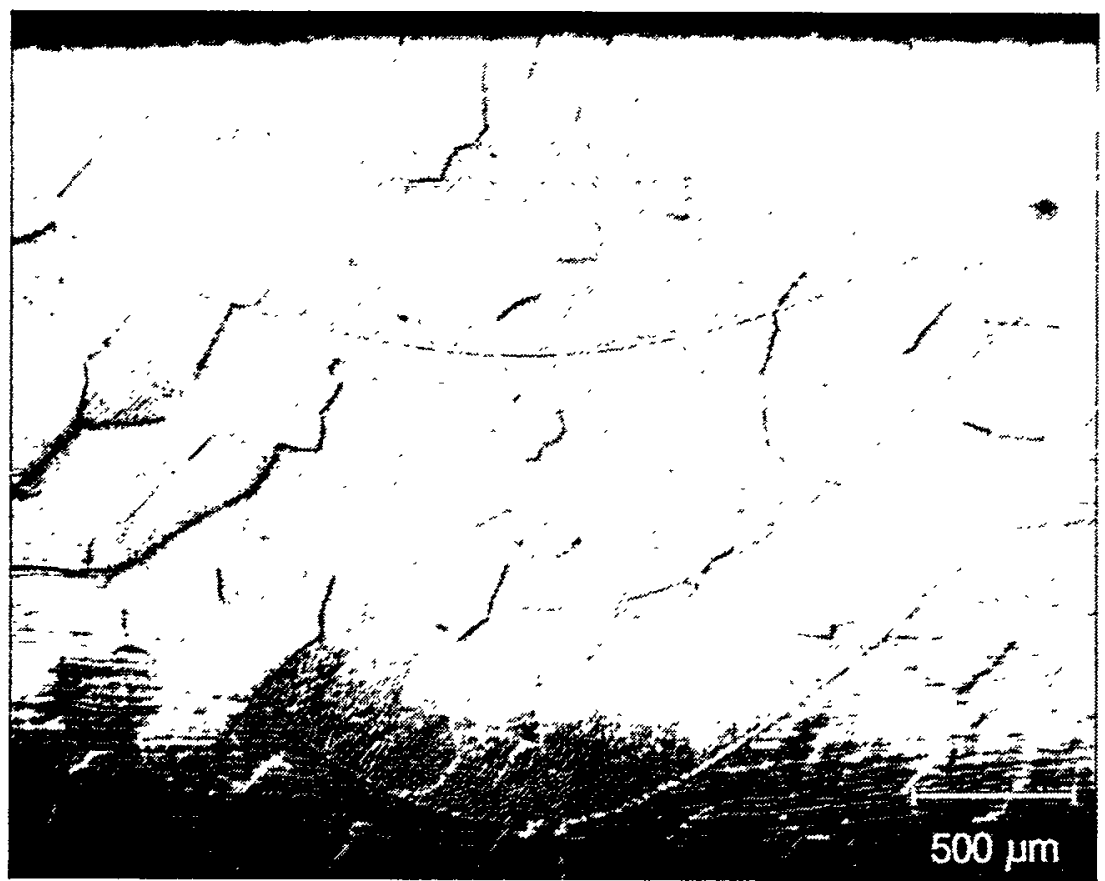

(b)

Figure 7 (a) and (b) Cross-sections of pulsed GTA weld in Ta-10W. Note pulse boundaries throughout the weld cross-section. 


\section{Conclusions}

In support of the Milliwatt Generator Life Assessment program, a glove box enclosed GTA welding station has been constructed and characterized. The system incorporates means for local control of the arc atmosphere so that a wide range of welding environments can easily be evaluated. The welding system used in the assembly is computer controlled, and can be operated in either continuous or pulsed modes. The system can therefore be used for detailed research studies of welding impurity effects, development of prototype weld schedules, or to mimic a significant range of production-like welding conditions. Fixturing for fabrication of high temperature creep test samples has been designed and constructed, and weld schedules for grip-tab and test welds have been developed. The microstructures of these welds have been evaluated and are consistent with those used during RTG production. 


\section{References}

(1) Westinghouse Electric Corp., T-111, "Tantalum Base Alloy, Refractory Metal", Special Technical Data 52-365, (1963).

(2) Westinghouse Specification PDS 30112-1.

(3) General Electric Specification 01-0015-01-D.

(4) D. R. Stoner and G. G. Lessmann, "Measurement and Control of Weld Chamber Atmospheres", Welding Journal Research Supplement, Vol. 44, No. 8, p. 337-s.

(5) G. G. Lessmann, "The Comparative Weldability of Refractory Metal Alloys", Welding Journal Research Supplement, Vol. 45, No. 12, p. 540-s.

(6) E. D. Brandon, Welding Procedure for Milliwatt Heat Source Components: I. Liner, II. Strength Member, III Clad, Los Alamos National Laboratory Specification, Specification Number MWG-NMT9-PP-6, (1980).

(7) T. W. Latimer and G. H. Reinhart, "Milliwatt Generator Project April 1986-March 1988", Loa Alamos National Laboratory Progress Report LA-12236-PR, (1992).

(8) B. D. Ritchey, K. E. Eckelmeyer, A. C. Kilgo, and B. B. McKenzie, "Milliwatt Generator Heat Source Shelf-Life-Related Pressure Burst Capsule Evaluations", Sandia Report SAND97-2609, (1997). 


\section{Appendix A - Piece Part Machining and Cleaning Procedures}

T-111 is sensitive very small amounts of contamination by iron, copper, zinc, or other common machine-room elements. (Ref. Private conversations with R.W. Buckman, Jr., 1999). Care must be taken therefore, to prevent contamination of the surfaces which are to be welded. The pieces that will be assembled into tensile specimens are cut from sheet stock of T-111 or $\mathrm{Ta} / 10 \mathrm{~W}$ using Electro-Discharge Machining (EDM). Specifications for this part of the process are written to allow the use of molybdenum wire only. Once they are cut, any grinding needed is performed using dedicated alumina wheels to avoid the possibility of cross-contamination. Finished parts are fully immersed in a mixture of equal parts: DI water, sulfuric acid, nitric acid, and hydrofluoric acid for a period of not less that 5 minutes. They are then rinsed in DI water, blotted dry, and moved to the glove box for dry storage. 


\section{Appendix B - Weld Schedule for Grip-Tab Attachment}

The following program, listed by each input screen, is stored as PULSTA on the hard-drive of the WeldLogic controller.

\section{System Modes}

XY type...

Pulse Mode...

Sequence Mode...

Autosequence Mode...

Stubout Mode... line

PPS

off

off

off

\section{Gas Parameters}

All are set to 0 (The AWS 2000 is not used to control gas flow)

\section{Current Parameters}

Start Current...

Upslope Time...

Level Slope...

Down Slope...

Finish Current....

Current Override Alarm...

Current Alarm High Limit...

Current Alarm Low Limit...

Current Shutdown High Limit...

Current Shutdown Low limit...

$30 \mathrm{amps}$
$.4 \mathrm{sec}$
$.0 \mathrm{sec}$
$3.5 \mathrm{sec}$
$30 \mathrm{amps}$
$5 \%$
$5 \%$
$5 \%$
$10 \%$
$10 \%$

.050 inches

$2.0 \mathrm{sec}$

$0 \mathrm{sec}$

.5 inches

$100 \%$

.0 volts

$5 \%$

$5 \%$

$5 \%$

$10 \%$

$10 \%$ 


\section{Travel Parameters}

Travel Parameters are provided to control rotation, but are not used with the current configuration.

\section{Wire Parameters}

Wire-feed control parameters are not used.

\section{XY Position Parameters}

Travel Start Delay Time...

$\mathrm{X}$ Axis - Start Position...

$1.5 \mathrm{sec}$

Y Axis - Start Position...

$\mathrm{X}$ Axis - Finish Position ...

Y Axis - Finish Position...

Slow XY Jog Speed...

Fast XY Jog Speed...

XY Position Parameters (cont.)

Transit Speed...

Autostart Position Move...

Return to Idle position...

Line X End Point...

Line $Y$ End Point...

\section{Level Parameters}

Peak Current...

Background Current...

AVC...

Peak Voltage...

Background Voltage...

Pulse Rate...

Pulse Width...

Travel Speed...

Surface Travel Speed...

Wire Mode...
.000 inches

.000 inches

.280 inches

.000 inches

$5 \%$

$25 \%$

$100 \%$

off

off

.280 inches

.000 inches

210 amps

60 amps

off

9.0 volts

.0 volts

1.5 PPS

$20 \%$

$.0 \mathrm{rpm}$

$2.4 \mathrm{ipm}$

off

This program configuration will produce weld beads .280 inches long along the $X$-axis. By changing the $\mathrm{X}$-axis Finish Point and End Point to .000 inches, and the $\mathrm{Y}$-axis Finish Point and End Point to .280 inches the final weld on the $Y$-axis is completed. Welds are started with the electrode directly above the joint, approximately 0.8 inches away from the edge of the sample to prevent slumping at the edge. The electrode is a $3 / 32$ inch, $98.5 \% \mathrm{~W}-1.5 \% \mathrm{La}_{2} \mathrm{O}_{3}$ 
electrode sharpened at a 25 degree included angle, and the system is configured Direct Current Electrode Negative. He80\%/Ar20\% shield gas is provided at a flow-rate of $40 \mathrm{SCFH}$ through a Helium flow meter. When the program is initiated, the electrode moves to the specified .050 arc gap (Start Gap) and the arc starts at 30 amps. Upslope to the 60-amp background current takes .4 seconds. The arc, set at a pulse rate of 1.5 pulses per second and a pulse width of $20 \%$, remains stationary for an additional 1.1 seconds to allow pool formation. Travel is then completed at a speed of 2.4 inches per minute. The current down slope to the specified level of $30 \mathrm{amps}$ is set such that it takes place over the last .14 inches (3.5 seconds) of travel. We have found that on a very short bead, this produces a more uniform width. When the travel is complete, the arc is extinguished and the electrode withdraws to a height of .5 inches above the sample. This completes the program, and the electrode can be moved using manual controls to the start position of the next weld. 


\section{Distribution}

Sandia National Laboratories

P.O. Box 5800

Albuquerque, NM 87185
Los Alamos National Laboratory

P.O. Box 1663

Los Alamos, NM 87545
Attn: MS-0342 Kenneth H. Eckelmeyer, 1822

MS-0367 Phillip W. Fuerschbach, 1833

MS-0367 Gerald A. Knorovsky, 1833

MS-0367 Mark Reece, 1833 (5)

MS-0367 Charles V. Robino, 1833 (5)

MS-0367 Mark F. Smith, 1833

MS-0367 John J. Stephens, 1833

MS-0443 Gerald W. Wellman, 9117

MS-0475 Ronald C. Hartwig, 2105

MS-0511 Brian K. Damkroger, 1002

MS-0525 William J. Kass, 2522

MS-0614 Bruce D. Fishel, 2522

MS-0614 Dennis E. Mitchell, 2522

MS-0834 Arthur C. Ratzel, 9112

MS-0834 Robert G. Schmitt, 9112

MS-0958 Bruce E. Swanson, 1484

MS-1407 Richard J. Salzbrenner, 1805

MS-0899 Technical Library, 4916

MS-9018 Central Technical Files, 8940-2

MS-0619 Review and Approval Desk, 00111

For DOE/OSTI

MS-E502 Martin A. Bowidowicz, NMT-9 